\title{
Genetic Characterization of 'Candidatus Liberibacter solanacearum' Haplotypes Associated with Apiaceous Crops in France
}

\author{
Ahmed Hajri, Marianne Loiseau, Pascaline Cousseau-Suhard, Isabelle Renaudin, and Pascal Gentit, ANSES-Laboratoire de la Santé des \\ Végétaux (LSV), 49044 Angers Cedex 01, France
}

\begin{abstract}
'Candidatus Liberibacter solanacearum' (Lso) is an emerging phytopathogenic bacterium that causes significant crop losses worldwide. This bacterium has been identified in association with diseases of several solanaceous crops in the United States and New Zealand, and with carrot and celery crops in several European countries. Five Lso haplotypes (LsoA, LsoB, LsoC, LsoD, and LsoE) have now been described worldwide. In France, symptoms of Lso were observed on plants of the Apiaceae family in several regions. One hundred and ninety-two samples of apiaceous plants were collected from 2012 to 2016 in different geographical regions and were tested for the occurrence of Lso by real-time PCR assay. In addition to carrot and celery, Lso was detected in four other apiaceous crops: chervil, fennel, parsley, and parsnip. These new findings suggest that Lso has a wider natural host range within the Apiaceae

family than expected. To identify the Lso haplotypes present in France, we sequenced and analyzed the 16S rRNA gene and the 50S ribosomal protein $r$ IJ -rpIL gene region from a representative bacterial collection of 44 Lso-positive samples. Our SNP analysis revealed the occurrence of two distinct bacterial lineages that correspond to haplotypes D and E. Then, we assessed the phylogenetic relationships between strains isolated from France and a worldwide collection of Lso isolates by using the rpIJ-rpIL gene region sequences. The neighbor-joining tree constructed delineated five clusters corresponding to the five Lso haplotypes, with LsoD and LsoE being closely related phylogenetically. Altogether, the data presented here constitute a first step toward a better understanding of the genetic diversity among Lso haplotypes in France, and provide new insights into the host range of this emerging bacterial species.
\end{abstract}

'Candidatus Liberibacter solanacearum' (Lso) is a phloem-limited, gram negative, unculturable plant pathogenic bacterium that spreads from infected to healthy plants by psyllid insect vectors. Lso was first identified as the causal agent of zebra chip (ZC) disease, which reduces both the yield and quality of potatoes (Solanum tuberosum), causing significant economic losses in North America and New Zealand (Hansen et al. 2008; Liefting et al. 2008a, 2009a; Lin et al. 2009). Apart from its association with ZC disease, this bacterium has been found to affect other solanaceous crops naturally, including tomato (S. lycopersicum), pepper (Capsicum annuum), eggplant (S. melongena), tamarillo (S. betaceum), tomatillo (Physalis spp.), tobacco (Nicotiana tabacum), and Cape gooseberry (Physalis peruviana) (Liefting et al. 2008b, 2009a; Ling et al. 2011). In Europe, Lso is associated with vegetative disorders in plants of the Apiaceae family, including carrot (Daucus carota) and celery (Apium graveolens) (Munyaneza et al. 2010a; Nelson et al. 2013; Teresani et al. 2014). Regarding the vectors, the bacterium is transmitted to solanaceous species by the potato/tomato psyllid Bactericera cockerelli (Munyaneza et al. 2007), and has been found in association with the psyllids Trioza apicalis and B. trigonica on carrot plants (Alfaro-Fernández et al. 2012a, b; Munyaneza et al. 2010b; Nissinen et al. 2014; Teresani et al. 2014, 2015). The natural host plant range of Lso seems to be restricted by the host range of the psyllid vectors. However, both the bacterium and the psyllids have acquired the ability to adapt rapidly to new hosts, following changes in vegetation and environmental factors (Haapalainen 2014). Previous reports have documented the association of Lso with several solanaceous weed species, such as silverleaf nightshade ( $S$. elaeagnifolium), black

Corresponding author: M. Loiseau; E-mail: marianne.loiseau@anses.fr

A. Hajri and M. Loiseau contributed equally to this work.

Disclaimer: The present work reflects only the author's view and the EU Funding Agency is not responsible for any use that may be made of the information it contains.

Accepted for publication 2 April 2017.

(c) 2017 The American Phytopathological Society nightshade (S. ptychanthum), and wolfberry (Lycium barbarum) in North America (Wen et al. 2009) and with Jerusalem cherry (S. pseudocapsicum) and thorn-apple (Datura stramonium) in New Zealand (Vereijssen et al. 2015). In contrast to the substantial host range of Lso within the solanaceous family, the host range of the bacterium within the Apiaceae family seems to be limited to carrot and celery plants (Haapalainen 2014; Munyaneza 2015), since weed species associated with apiaceous crops in the southeast of Spain were not reported to act as reservoirs for Lso (Alfaro-Fernández et al. 2016). Therefore, the identification of new and potential alternative hosts for Lso is important for a better understanding of the epidemiology of the disease and its management.

Information regarding the population structure and genetic diversity, as well as the phylogenetic relationships of Lso isolates across different geographical regions and hosts, is limited, in particular due to its fastidious nature. The isolates of Lso originating from different geographical areas were allocated to five different haplotypes (LsoA, LsoB, LsoC, LsoD, and LsoE). These haplotypes were characterized based on single-nucleotide polymorphism (SNP) genotyping of the 16S rRNA gene, 16S/23S ISR, and 50S ribosomal protein rpIJ-rpIL gene region (Nelson et al. 2011, 2013; Teresani et al. 2014). Haplotypes A and B are associated with several solanaceous crops where they are transmitted by B. cockerelli. Haplotype A has been found primarily in Honduras and Guatemala, through western Mexico to Arizona and California, and in New Zealand. Haplotype $\mathrm{B}$ is currently known in eastern Mexico and northward through Texas to south central Washington (Nelson et al. 2011). Haplotype $C$ has been detected on infected carrots in northern Europe (Finland, Norway, Sweden, and Germany) and in association with T. apicalis (Munyaneza et al. 2010a, 2012a, b, 2015), whereas haplotype D has been associated with carrots and B. trigonica in Spain and the Canary Islands (Alfaro-Fernández et al. 2012a, b; Nelson et al. 2013). Finally, the recently described haplotype $\mathrm{E}$ has been associated with carrot and celery plants and B. trigonica in Spain (Teresani et al. 2014). Lso haplotypes have thus been defined not only genetically but also by geographic distribution, as well as by plant and psyllid association (Munyaneza 2015).

Elucidation of the genetic basis of the interactions between Lso haplotypes and their host plants is a fascinating question that has been accelerated by advances in genomic sequencing. Like in other ' $\mathrm{Ca}$. Liberibacter' species, the genome of Lso was shown to contain genetic 
features distinctive to obligate intracellular bacteria, such as having a significantly reduced genome $(1.2 \mathrm{Mb})$ and a low GC content $(\sim 35 \%)$ (Lin and Gudmestad 2013). With the publication of the first Lso genome sequence (Lin et al. 2011), several genetic studies on variability of solanaceous haplotypes (LsoA and LsoB) using multilocus sequence typing (MLST) and simple sequence repeat (SSR) markers were performed. The resulting diversity studies using these markers revealed limited genetic variation among Lso isolates with two lineages in the United States (ST-1, ST-2) and only one lineage in Mexico (ST-1) and New Zealand (ST-2). In addition, no clear genetic structure was established among solanaceous Lso haplotypes (LsoA and LsoB) based on the geographic origin or the host (Glynn et al. 2012; Lin et al. 2012). Interestingly, the two lineages identified by MLST and SSR techniques correspond to haplotypes A and B, previously described on the basis of the sequencing of ribosomal genes (Nelson et al. 2011; Secor et al. 2009; Wen et al. 2009). Therefore, haplotyping with the method of Nelson et al. (2011) was considered more accurate for the description of the genetic diversity of Lso and for establishing a possible association with the geographical origin (Haapalainen 2014; Lin and Gudmestad 2013; Munyaneza 2015). For apiaceous cropinfecting Lso haplotypes (LsoC, LsoD, and LsoE), no genetic studies have been performed and the current knowledge is limited to the first reports of the bacterium in many European countries (Alfaro-Fernández et al. 2012a, b; Loiseau et al. 2014; Munyaneza et al. 2010a, 2012a, b, 2015; Teresani et al. 2014) and in Morocco (Tahzima et al. 2014).

The objective of the present study was to identify the Lso haplotypes present in France. For this purpose, we examined the genetic diversity of Lso isolates on several apiaceous crops by sequencing the 16S rRNA gene and the 50S ribosomal protein rpIJ-rpIL gene region. We selected these two loci because they were used in several first reports of the bacterium (Alfaro-Fernández et al. 2012a, b; Munyaneza et al. 2010a, 2012a, b; Tahzima et al. 2014). The French Lso isolates used reflect a diversity of collection dates, geographic locations, and host plants. The rpIJ-rpIL gene region was used to assess the phylogenetic relatedness between Lso haplotypes detected in France and other known Lso haplotypes (Nelson et al. 2011, 2013; Teresani et al. 2014). The results of this research can help to further elucidate the disease etiology and epidemiology, and the driving forces that might contribute to the spread of this emerging bacterial species in new crops.

\section{Materials and Methods}

Plant material. Between 2012 and 2016, symptoms similar to those associated with Lso (Munyaneza et al. 2010b) were observed on several apiaceous crops (carrot - Daucus carota, celery - Apium graveolens, chervil - Anthriscus cerefolium, fennel - Foeniculum vulgare, parsley - Petroselinum crispum, and parsnip - Pastinaca sativa) in several regions of France. A total of 192 plant samples were analyzed in this study (Table 1).
DNA extraction. Total DNA was extracted from the 192 apiaceous plant samples collected from 2012 to 2016 using a slightly modified cetyltrimethylammonium bromide (CTAB) buffer extraction method (Murray and Thompson 1980). For each sample, $1 \mathrm{~g}$ of petiole tissue was ground into a plastic bag (Bioreba AG, Basel, Switzerland) with pneumatic press in $8 \mathrm{ml}$ of CTAB buffer (3\%). Afterward, $1 \mathrm{ml}$ of the supernatant was transferred to an Eppendorf tube, then mixed with $2 \mu$ l of $\beta$-mercaptoethanol $(0.2 \%)$ and incubated for $20 \mathrm{~min}$ at $65^{\circ} \mathrm{C}$. After incubation, an equal volume of chloroform/isoamylic alcohol (24:1) was added. Samples were vortexed and centrifuged at $10,000 \times g$ for $10 \mathrm{~min}$. Then, $750 \mu \mathrm{l}$ of the aqueous layer was transferred to a new Eppendorf tube containing $750 \mu \mathrm{l}$ of cold isopropanol. DNA was recovered by centrifugation at $10,000 \times g$ for $15 \mathrm{~min}$. The pellet was washed with ice-cold $90 \%$ ethanol and centrifuged at $10,000 \times g$ for $10 \mathrm{~min}$. After removal of ethanol, the pellet was air-dried, then resuspended in $100 \mu 1$ DNase-free water and stored at $-20^{\circ} \mathrm{C}$ until use. Each extraction series contained positive and negative controls.

Detection of Lso by real-time PCR. Total genomic DNA isolated from the 192 samples was tested for the presence of Lso by real-time PCR as previously described ( $\mathrm{Li}$ et al. 2009). The reaction mix consisted of 1× TaqMan Universal Master Mix (Applied Biosystems, Foster City, CA), $0.24 \mu \mathrm{M}$ forward primer LsoF, $0.24 \mu \mathrm{M}$ reverse primer HLBr, and $0.12 \mu \mathrm{M}$ HLBp TaqMan probe (Table 2). Five microliters of total DNA extract (undiluted and diluted 10 times in DNase-free water) were added to the reaction mix for a final volume of $25 \mu \mathrm{l}$. The real-time PCR program was one cycle at $95^{\circ} \mathrm{C}$ for $10 \mathrm{~min}$ and 45 cycles at $95^{\circ} \mathrm{C}$ for $15 \mathrm{~s}$, and at $60^{\circ} \mathrm{C}$ for $1 \mathrm{~min}$. The presence of the target sequences in the DNA extracts was confirmed based on the threshold cycle $(\mathrm{Ct})$ values obtained. Each reaction contained a positive DNA control and a nontemplate water control.

Lso haplotype determination by PCR and sequencing. Once the presence of Lso in tested samples was confirmed using realtime PCR (Li et al. 2009), we built up a working collection of 44 isolates for Lso haplotyping (Table 3). In order to provide the largest possible diversity, these isolates were chosen to represent different geographical regions and host plants. The Lso haplotypes were determined on the basis of SNPs on the 16S rRNA gene and the 50S ribosomal protein $r p I J$-rpIL gene region, following the method of Nelson et al. $(2011,2013)$. For this purpose, PCRs were performed using specific primer pairs OA2/OI2c and CL514F/R (Table 2), which amplify DNA sequences from the two ribosomal regions, respectively.

For $16 \mathrm{~S}$ rRNA, PCR assays were performed in a $25 \mu$ l reaction mix consisting of $1 \times$ PCR buffer, $1.5 \mathrm{mM} \mathrm{MgCl}_{2}, 0.2 \mathrm{mM}$ of each dNTP, $0.25 \mu \mathrm{M}$ of primer OA2 and OI2c, 1 U Platinum Taq DNA polymerase (Invitrogen, Carlsbad, CA), and $5 \mu$ l of total DNA. The conditions for amplification were: initial denaturation at $94^{\circ} \mathrm{C}$ for $5 \mathrm{~min}$, followed by 40 cycles at $94^{\circ} \mathrm{C}$ for $30 \mathrm{~s}, 65^{\circ} \mathrm{C}$ for $30 \mathrm{~s}$, and $72^{\circ} \mathrm{C}$ for $1 \mathrm{~min}$, with a final extension at $72^{\circ} \mathrm{C}$ for $10 \mathrm{~min}$. For

Table 1. Results of 'Candidatus Liberibacter solanacearum' PCR testing for apiaceous samples collected at different locations of France

\begin{tabular}{|c|c|c|c|c|c|}
\hline Year of sampling & $\begin{array}{c}\text { Geographic location } \\
\text { (department) }\end{array}$ & Species & Symptoms status & $\begin{array}{c}\text { Number of } \\
\text { tested samples }\end{array}$ & $\begin{array}{l}\text { Positive } \\
\text { samples }\end{array}$ \\
\hline 2012 & Loir-et-Cher & Daucus carota & Symptomatic & 4 & 4 \\
\hline 2013 & Dordogne & Daucus carota & Symptomatic & 2 & 2 \\
\hline 2014 & Gard & Daucus carota & Symptomatic & 3 & 3 \\
\hline 2014 & Loiret & Daucus carota & Symptomatic & 1 & 1 \\
\hline 2014 & Eure-et-Loir & Daucus carota & Symptomatic & 1 & 1 \\
\hline 2014 & Maine-et-Loire & Daucus carota & Symptomatic & 74 & 74 \\
\hline 2014 & Maine-et-Loire & Daucus carota & Asymptomatic & 72 & 56 \\
\hline 2014 & Maine-et-Loire & Apium graveolens & Symptomatic & 9 & 4 \\
\hline 2014 & Maine-et-Loire & Anthriscus cerefolium & Symptomatic & 2 & 2 \\
\hline 2014 & Maine-et-Loire & Petroselinum crispum & Symptomatic & 5 & 4 \\
\hline 2014 & Maine-et-Loire & Foeniculum vulgare & Asymptomatic & 5 & 1 \\
\hline 2014 & Maine-et-Loire & Pastinaca sativa & Asymptomatic & 5 & 4 \\
\hline 2016 & Eure-et-Loir & Daucus carota & Symptomatic & 1 & 1 \\
\hline 2016 & Maine-et-Loire & Daucus carota & Symptomatic & 5 & 5 \\
\hline 2016 & Gers & Daucus carota & Symptomatic & 3 & 3 \\
\hline
\end{tabular}


the $r p I J-r p I L$ gene region, PCR assays were performed in a $25 \mu l$ reaction using the Bio-X-Act short polymerase mix (Bioline, London, U.K.), $0.4 \mu \mathrm{M}$ of primer CL514F and CL514R, and $2 \mu \mathrm{l}$ of DNA. PCR amplification consisted of one cycle at $95^{\circ} \mathrm{C}$ for $5 \mathrm{~min}$, followed by 40 cycles at $94^{\circ} \mathrm{C}$ for $30 \mathrm{~s}, 53^{\circ} \mathrm{C}$ for $30 \mathrm{~s}$, and $72^{\circ} \mathrm{C}$ for $30 \mathrm{~s}$, and extension with one cycle at $72^{\circ} \mathrm{C}$ for $7 \mathrm{~min}$.

All PCR series included negative and positive controls. Amplified PCR products were separated on $1.5 \%$ agarose gels containing ethidium bromide for visualization. All positive amplicons obtained from these PCR assays were directly sequenced in both directions (Genewiz, Takeley, U.K.). Forward and reverse nucleotide sequences were edited, assembled, and concatenated using the GENEIOUS software (version R7 7.0.6) (Kearse et al. 2012). Sequences were aligned against representative Lso sequences of the five previously described haplotypes, which are available in GenBank. Multiple alignments were manually edited using the BIOEDIT program version 7.2.5 (Hall 1999). The SNPs were visually identified and recorded following the method of Nelson et al. $(2011,2013)$.

Molecular evolutionary analyses and phylogenetic analysis. For population genetic analyses, the $16 \mathrm{~S}$ and $r p I J-r p I L$ gene region sequences generated from the studied isolates from France were aligned with Lso sequences retrieved from GenBank. Only Lso isolates for which both $16 \mathrm{~S}$ and $r p I J-r p I L$ gene region sequences are available were considered for calculation of the genetic diversity parameters. Nucleotide diversity was analyzed by estimating $\theta_{\pi}$ (the average number of nucleotide differences per site between two sequences, Nei 1987) and $\theta_{\mathrm{w}}$ (estimate of the population mutation rate, Watterson 1975). The test statistic D (Tajima 1989) was used to compare these summary statistics. Tajima's D tests the hypothesis that all

Table 2. Primers used for 'Candidatus Liberibacter solanacearum' detection and haplotype identification

\begin{tabular}{lll}
\hline $\begin{array}{l}\text { Primer } \\
\text { name }\end{array}$ & \multicolumn{1}{c}{ Sequence 5' -3' $^{\prime}$} & \multicolumn{1}{c}{ Reference } \\
\hline LsoF & GTCGAGCGCTTATTTTTAATA & Li et al. (2009) \\
& GGA & \\
HLBr & GCGTTATCCCGTAGAAAAAGG & Li et al. (2006) \\
& TAG & Li et al. (2006) \\
HLBp & FAM-AGACGGGTGAGTAAC & \\
& GCG-BHQ1 & \\
OA2 & GCGCTTATTTTTAATAGGAGCG & Liefting et al. (2009b) \\
& GCA & \\
OI2c & GCCTCGCGACTTCGCAACCCAT & Jagoueix et al. (1996) \\
CL514F & CTCTAAGATTTCGGTTGGTT & Munyaneza et al. (2009) \\
CL514R & TATATCTATCGTTGCACCAG & Munyaneza et al. (2009) \\
\hline
\end{tabular}

mutations are selectively neutral and measures the differences between the population mutation rates and the average number of nucleotide differences. To assess departure from the neutral model, two other tests were applied using Fu and Li's $\mathrm{D}^{*}$ and $\mathrm{F}^{*}$ (Fu and Li 1993) statistics; $D *$ is based on the difference between the number of singletons and the total number of mutations, whereas $\mathrm{F}^{*}$ is based on the difference between the number of singletons and the average number of nucleotides. All these parameters were estimated for each of the genes using DNASP version 5.10.01 (Librado and Rozas 2009).

The phylogenetic analysis was performed to establish the phylogenetic relatedness between the Lso isolates collected in France (Table 3) and Lso isolates from other regions of the world: Spain (HQ454305, HQ454306, HQ454307, HQ454310, HQ454311, JX308305), Canary Islands (HQ454317, HQ454318, HQ454319, HQ454320), Morocco (KJ754506, KJ754507), Finland (JX280522), Sweden (JX280520, JN863093), Norway (JX280521, JN863098), New Zealand (EU919514), Mexico (JF811599, FJ498807, FJ957895), and the United States (FJ498803). This phylogenetic analysis was performed by analyzing sequences of the rpIJ-rpIL gene region. Sequences were aligned using the BIOEDIT program version 7.2.5 (Hall 1999). A neighbor-joining tree was generated based on the alignments with the MEGA 7.0.14 software program (Kumar et al. 2016) using the Kimura twoparameter model (Kimura 1980). Statistical confidence of tree topology was assessed by 1,000 bootstrap replications, and the tree was rooted using the corresponding $r p I J$-rpIL sequence of ' $\mathrm{Ca}$. L. asiaticus' strain psy62 (Duan et al. 2009) as an outgroup.

Nucleotide sequence accession numbers. The sequences reported in this study were deposited in GenBank under accession numbers: KY229076 to KY229119 for the 16S rRNA gene and KY229120 to KY229157 for the rpIJ-rpIL gene region.

\section{Results}

Lso detection. Symptoms of proliferation of shoots, yellowing and curling of leaves, proliferation of secondary roots, and plant stunting were observed on infected carrots and other collected apiaceous crops (celery, parsley, and chervil) as well (Fig. 1). No typical symptoms were observed on fennel and parsnip. Out of the 192 samples collected in this study, all 94 carrot samples collected from symptomatic plants were positive for Lso with $\mathrm{Ct}$ values ranging from 17 to 32 . On asymptomatic carrot samples, 56 were positive and 16 samples were negative. Fifteen out of the 26 apiaceous samples other than carrot were positive for the occurrence of Lso (Ct between 21 and 35).

Haplotype identification. All DNAs from the 44 samples selected for genetic analysis (Table 3) yielded amplicons of the expected length $(1,168 \mathrm{bp})$ for the $16 \mathrm{~S}$ gene. For the $r p I J$-rpIL gene region,

Table 3. List of 'Candidatus Liberibacter solanacearum' isolates from France used for haplotyping

\begin{tabular}{llll}
\hline $\begin{array}{l}\text { Year of } \\
\text { sampling }\end{array}$ & $\begin{array}{c}\text { Geographic } \\
\text { location (department) }\end{array}$ & Host plant & Sample ID \\
\hline 2012 & Loir-et-Cher & carrot & $12 / 281 ; 12 / 379.2 ; 12 / 379.8$ \\
2013 & Dordogne & carrot & $13 / 479.1 ; 13 / 479.2$ \\
2014 & carrot & $14 / 427.2 ; 14 / 427.3 ; 14 / 427.13$ \\
& Gard & carrot & $14 / 235$ \\
& Loiret & carrot & $14 / 244$ \\
& Eure-et-Loir & carrot & $14 / 362.11 ; 14 / 362.26 ; 14 / 362.39 ; 14 / 362.41 ; 14 / 362.58 ; 14 / 362.61 ; 14 / 362.62 ;$ \\
& Maine-et-Loire & & $14 / 362.63 ; 14 / 382.10 ; 14 / 382.18 ; 14 / 382.20 ; 14 / 382.24 ; 14 / 382.40 ; 14 /$ \\
& & $382.45 ; 14 / 382.70$ \\
2016 & celery & $14 / 363.3$ \\
& & chervil & $14 / 367.1 ; 14 / 386.1$ \\
& fennel & $14 / 366.1$ \\
& & parsley & $14 / 364.1 ; 14 / 364.2 ; 14 / 384.2$ \\
& parsnip & $14 / 365.1 ; 14 / 365.2 ; 14 / 365.3 ; 14 / 365.4$ \\
& Eure-et-Loir & $16 / 91.2-3 \mathrm{~m}$ \\
& Maine-et-Loire & carrot & $16 / 119.1-1 ; 16 / 119.1-2 ; 16 / 119.1-3 ; 16 / 119.1-4$ \\
& Maine-et-Loire & carrot & $16 / 120.2 \mathrm{c}$ \\
& Gers & carrot & $16 / 122.2 ; 16 / 122.3$ \\
\hline
\end{tabular}


a PCR product of $669 \mathrm{bp}$ was obtained from 38 out of the 44 DNA samples. No amplification was observed in DNA isolated from healthy carrot plants and in nontemplate water controls. These results confirm the presence of Lso in the six apiaceous crops (carrot, celery, chervil, fennel, parsley, and parsnip) sampled in this study.

Following alignment of sequences of the French Lso isolates obtained in this work and representative Lso isolates from the five known haplotypes, SNP variations across the isolates were assessed on a common 708 bp sequence of the $16 \mathrm{~S}$ gene and a common $523 \mathrm{bp}$ sequence of the rpIJ-rpIL gene region. According to the method of Nelson et al. (2011, 2013), the tested isolates were divided into five groups based on their SNP patterns in each of the two ribosomal gene regions, supporting the delineation of five genetic variants (or haplotypes) within the tested Lso isolates.

Interestingly, the 44 Lso strains isolated in France belonged to haplotypes D and E. Both haplotypes were differentiated by three nucleotide changes in the $16 \mathrm{~S}$ gene and five in the rpIJ-rpIL gene region (Table 4). Among carrot samples, the three tested isolates collected in 2012 belonged to LsoE, the two isolates collected in 2013 belonged to LsoD, and both haplotypes were detected in the samples collected in 2014 and 2016. On the apiaceous crops other than carrots, all the tested samples were infected with LsoE.

On the 16S gene, there is no evidence at all of combinations of SNPs within a gene region across the five haplotypes. For the $r p I J$ $r p I L$ gene region, we detected one recombination event in two strains isolated from Spain (JX308305, HQ454307). The rpIJ-rpIL gene region sequences from these two isolates exhibited the same SNPs described for $\mathrm{LsoD}$, with a single exception, the presence of $\mathrm{C}$ instead of A at position 749 (Table 4).

Polymorphism analysis. Summary statistics describing the sequence diversity of the $16 \mathrm{~S}$ gene and the rpIJ-rpIL gene region are presented in Table 5. The average GC content is $37.2 \%$ for the rpIJ-rpIL gene region and $51.5 \%$ for the $16 \mathrm{~S}$ gene. Nucleotide diversity $\left(\theta_{\pi}\right)$ and Watterson's theta $\left(\theta_{\mathrm{w}}\right)$ showed greater sequence variation in our sample of Lso isolates for the rpIJ-rpIL gene region
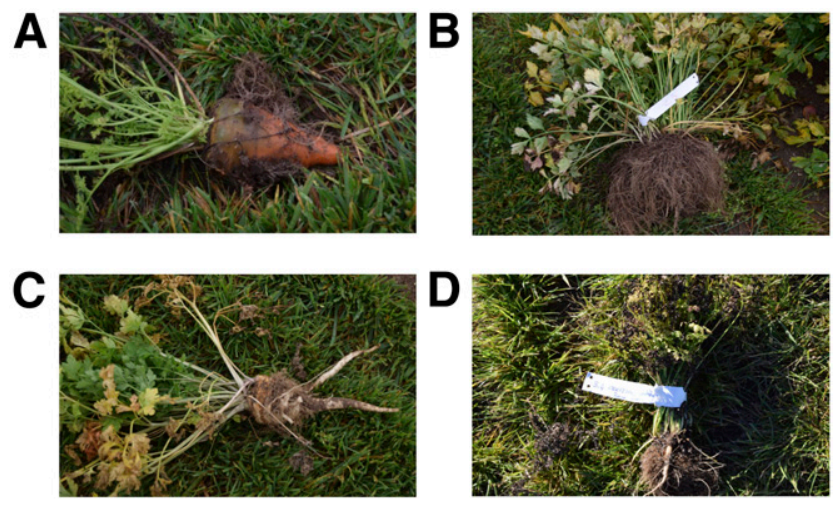

Fig. 1. Symptoms associated with 'Candidatus Liberibacter solanacearum' on apiaceous crops: (A) carrot, (B) celery, (C) parsley, (D) chervil. Observed symptoms include proliferation of shoots, discoloration of leaves, curled stems, and formation of hairy secondary roots. $\left(\theta_{\pi}=0.00771, \theta_{\mathrm{w}}=0.00842\right)$ than for the $16 \mathrm{~S}$ gene $\left(\theta_{\pi}=0.00220\right.$, $\left.\theta_{\mathrm{w}}=0.00123\right)$. The percentage of variable sites is $0.56 \%$ for the $16 \mathrm{~S}$ gene and $3.82 \%$ for the $r p I J$-rpIL gene region, indicating that Lso is more heterogeneous across isolates on the $r p I J$-rpIL gene region. Our analyses, combined with the observation that the rpIJ-rpIL gene region has a GC content $(37.2 \%)$ similar to the average value $(\sim 35 \%)$ of the Lso genome, collectively suggest that the rpIJ-rpIL gene region is more suitable for the phylogenetic analysis of Lso. Furthermore, in the case of the $16 \mathrm{~S}$ gene, neutrality tests (Tajima's $\mathrm{D}, \mathrm{Fu}$ and $\mathrm{Li}^{\prime} \mathrm{S} \mathrm{D}^{*}$ and $\mathrm{F}^{*}$ ) indicated that no departure from mutation/drift equilibrium was detected on the overall dataset. However, significant departure was observed for the rpIJ-rpIL gene region with the Fu and Li's D* test, but not with the two other tests (Tajima's D and Fu and Li's F*).

Phylogenetic analysis. For our phylogenetic analysis, we selected the $r p I J$-rpIL gene region because it appears as the most polymorphic gene among the ribosomal genes analyzed in this study. A collection of 60 Lso sequences was used for our phylogenetic analysis. This collection consists of the $38 \mathrm{rpIJ}-r \mathrm{r} I L$ gene region sequences obtained from the isolates collected in this study, and 22 rpIJ-rpIL gene region sequences from other regions of the world. The neighbor-joining tree, rooted with the ortholog rpIJ-rpIL gene region sequence from ' $C a$. L. asiaticus' strain psy62, is presented in Figure 2. According to the results of this phylogenetic analysis, the 60 tested Lso isolates were clustered into five groups that correspond to the five known Lso haplotypes. High bootstrap values indicated that this clustering was well supported and that the tree was robust.

The first group (LsoE) included the majority of isolates collected in France on various apiaceous plants (carrot, chervil, parsley, and parsnip) at different locations and at different times (2012, 2014, and 2016). In addition to the isolates detected in France, the LsoE group contained one strain from Morocco isolated from carrot plants. The second group (LsoD) contained 11 strains from France isolated from carrot plants at different times (2013, 2014, and 2016), one strain from Morocco isolated from carrots, eight strains from Spain isolated from carrots, and two strains also from Spain isolated from celery. Clustering of strains isolated in France was not explained by their geographical origin since overlapping of both haplotypes (LsoD and LsoE) was observed in the same geographical location (i.e., Maine-et-Loire). The third group (LsoA) was identified from one strain isolated from potatoes from the United States, one strain isolated from tomatoes from Mexico, and one strain isolated from potatoes from New Zealand. The fourth group (LsoC) contained strains isolated from carrot plants in Scandinavian countries (Finland, Norway, and Sweden). The fifth group (LsoB) contained two strains isolated from tomatoes and potatoes from Mexico.

Concerning the divergence of Lso isolates, our phylogenetic tree showed that LsoB, LsoC, and LsoA isolates form groups that would have diverged first, followed by the cluster formed by LsoD and LsoE. With regard to the genetic relatedness of Lso strains isolated on apiaceous crops, LsoD and LsoE appeared to be very close phylogenetically. However, strains identified as LsoC haplotype form a distinct cluster separated from the other apiaceous haplotypes (LsoD and LsoE), although they cause disease on apiaceous plants as well. Intrahaplotype variation was observed only within LsoD where two isolates from Spain (JX308305, HQ454307) exhibited a different

Table 4. SNP genetic lineages and haplotype distribution among 'Candidatus Liberibacter solanacearum' isolates from France used in this study ${ }^{\mathrm{a}}$

\begin{tabular}{|c|c|c|c|c|c|c|c|c|c|}
\hline \multirow[b]{2}{*}{ Haplotype } & \multirow[b]{2}{*}{ Sample ID of the isolates } & \multicolumn{3}{|c|}{ SNPs on the $16 S$} & \multicolumn{5}{|c|}{ SNPs on the $r p I J-r p I L$} \\
\hline & & 959 & 1039 & $\overline{1073}$ & 622 & 700 & 722 & 749 & $\overline{1068}$ \\
\hline $\mathrm{D}$ & $\begin{array}{l}\text { 13/479.1, 13/479.2, 14/427.2, 14/362.61, 14/362.63, 14/382.10, 14/382.20, } \\
\text { 14/382.24, 16/91.2-3m, 16/122.2, 16/122.3 }\end{array}$ & $\mathrm{C}$ & $\mathrm{G}$ & A & G & G & $\mathrm{G}$ & A & $\mathrm{T}$ \\
\hline $\mathrm{E}$ & $\begin{array}{c}12 / 281,12 / 379.2,12 / 379.8,14 / 427.3,14 / 427.13,14 / 235,14 / 244,14 / 362.11 \\
14 / 362.26,14 / 362.39,14 / 362.41,14 / 362.58,14 / 362.62,14 / 382.18 \\
14 / 382.40,14 / 382.45,14 / 382.70,14 / 363.3,14 / 367.1,14 / 386.1,14 / 366.1 \\
\text { 14/364.1, } 14 / 364.2,14 / 384.2,14 / 365.1,14 / 365.2,14 / 365.3,14 / 365.4 \\
16 / 119.1-1,16 / 119.1-2,16 / 119.1-3,16 / 119.1-4,16 / 120.2 \mathrm{c}\end{array}$ & $\mathrm{T}$ & A & $\mathrm{G}$ & A & A & A & $\mathrm{C}$ & $\mathrm{C}$ \\
\hline
\end{tabular}

\footnotetext{
a Nucleotide numbers count from the beginning of the same reference sequences used by Nelson et al. $(2011,2013)$.
} 
allele from the other LsoD isolates which could be due to a recombination event between LsoD and LsoE haplotypes.

\section{Discussion}

Lso is a bacterium of major economic impact that was first identified in association with diseases of several solanaceous crops in Mexico, the United States, and New Zealand. In the European and Mediterranean regions, Lso is associated with diseases of the Apiaceae family, mainly carrot and celery (Haapalainen 2014; Soliman et al. 2013). In France, Lso was first reported on carrot (Loiseau et al. 2014). In the frame of the present work, we provide evidence for the association of Lso with several new apiaceous crops (celery, chervil, fennel, parsley, and parsnip) in France. To the best of our knowledge, this is the first report of Lso infecting chervil, fennel, parsley, and parsnip, indicating that the pathogen has a broader host range within the Apiaceae family than expected. Identifying such new alternative hosts of Lso is crucial for a better understanding of the disease epidemiology and for management. The role of alternative host plants, especially solanaceous weeds as potential reservoirs for Lso, was previously documented for bittersweet nightshade (S. dulcamara) in the Columbia Basin of eastern Oregon (Murphy et al. 2014) and for silverleaf nightshade (S. elaeagnifolium) in Texas (Thinakaran et al. 2015). A more recent study conducted in Spain failed to show a role of weed species surrounding carrot and celery crops as reservoirs for Lso infection (Alfaro-Fernández et al. 2016). In France, several weed species grow in carrot production areas, raising concern about the role these plants might play in the spread of the pathogen. Whether these weed species can act as potential reservoirs of Lso was not investigated in this study but remains to be determined.

Another important finding of this study concerned the characterization of Lso haplotypes in France. Using two independent PCRbased genotyping strategies, our SNP analysis revealed that the 44 tested isolates belong to either haplotypes D or E. Strains of these two haplotypes were previously found infecting carrot plants in the Canary Islands, Spain, and Morocco (Alfaro-Fernández et al. 2012a, b; Nelson et al. 2013; Tahzima et al. 2014) and celery in Spain (Teresani et al. 2014). In our study, LsoD was detected on carrot plants sampled in many regions of France in 2013, 2014, and 2016. LsoE was recovered from several carrots sampled in 2012, 2014, and 2016 and from all other apiaceous crops (celery, chervil, fennel, parsley, and parsnip) sampled from one field located in the Maine-et-Loire Department in 2014. The presence of both haplotypes on apiaceous crops across different geographical regions suggests that no relationship could be established among the Lso haplotypes from France based on their geographic origin. Similar results were reported for solanaceous haplotypes (LsoA and LsoB) on

Table 5. Evaluation of the genetic diversity criteria of the $16 \mathrm{~S}$ gene and rpIJ-rpIL gene region among 'Candidatus Liberibacter solanacearum' isolates used in this study

\begin{tabular}{lcc}
\hline & \multicolumn{2}{c}{ Ribosomal gene } \\
\cline { 2 - 3 } Genetic diversity criteria & $\mathbf{1 6 S}$ & $\boldsymbol{r p I J - r \boldsymbol { I I L }}$ \\
\hline Fragment size (bp) & 708 & 523 \\
GC content (\%) & 51.5 & 37.2 \\
$\mathrm{~S}^{\mathrm{a}}$ & 4 & 20 \\
Percentage of variable sites & 0.56 & 3.82 \\
$\theta_{\pi}{ }^{\mathrm{b}}$ & 0.00220 & 0.00771 \\
$\theta_{\mathrm{w}}{ }^{\mathrm{c}}$ & 0.00123 & 0.00842 \\
Tajima's D & $1.7358^{\mathrm{d}}$ & $-0.2649^{\mathrm{e}}$ \\
Fu and Li's D & $0.9952^{\mathrm{e}}$ & $1.6958^{\mathrm{f}}$ \\
Fu and Li's F & $1.4309^{\mathrm{e}}$ & $1.1978^{\mathrm{e}}$ \\
\hline
\end{tabular}

\footnotetext{
${ }^{a}$ Number of polymorphic sites.

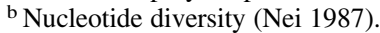

${ }^{c}$ Nucleotide diversity with Watterson's estimator (Watterson 1975).

${ }^{\mathrm{d}}$ Not significant, $0.05<P<0.10$

e Not significant, $P>0.10$.

${ }^{\mathrm{f}}$ Significant, $P<0.02$.
}

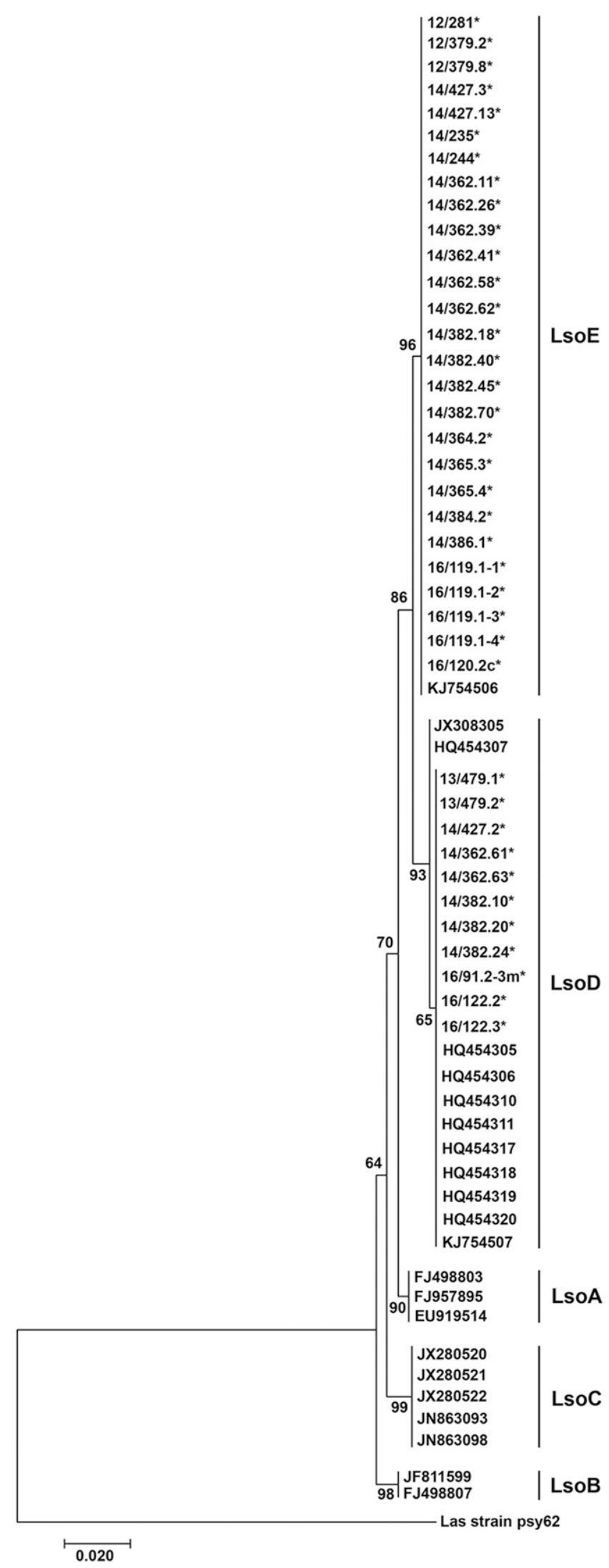

Fig. 2. Evolutionary relationships among 'Candidatus Liberibacter solanacearum' isolates based on sequences of the rplJ-rplL gene region. LsoA, LsoB, LsoC, LsoD, and LsoE refer to the five Lso haplotypes. Lso isolates from France obtained in this work are marked with an asterisk. GenBank accession numbers correspond to sequences of the rp/J-rplL gene region of Lso reference strains which were included for comparative purposes. The phylogenetic tree was constructed using the neighborjoining method. The confidence of nodes was tested with 1,000 bootstrap replicates. The scale represents the number of substitutions per site. The tree is rooted with the corresponding $r p / J-r p / L$ sequence of 'Ca. L. asiaticus' strain psy62. 
potatoes in the United States, where overlapping of identical haplotypes in different geographical locations was documented (Wen et al. 2013). Interestingly, the coexistence of LsoE on carrot plants and on other apiaceous crops (celery, chervil, fennel, parsley, and parsnip) grown in the same area may support the hypothesis that carrot would be the probable source of inoculum. The same observation was previously reported in Spain where LsoE was associated with celery grown next to carrots, suggesting that natural transmission of Lso between several apiaceous crops may occur (Teresani et al. 2014). So far, biological differences among apiaceous Lso haplotypes, including how they develop on various host plants and how they differ in aggressiveness, have not been studied. For solanaceous haplotypes, previous reports revealed that the symptomatology of ZC disease in New Zealand was different and less severe than in the United States (Pitman et al. 2011). Differences in ZC symptomatology have also been reported in Texas, where LsoB appeared to be more virulent than LsoA (Wen et al. 2013). Further work on the biological traits of Lso isolates from France on apiaceous crops and their occurrence in different geographical locations is now needed to better understand the interactions between the Lso haplotypes observed in France and the new alternative host plants reported in this paper.

The results of this study raise interesting questions concerning the origin of this disease in France. Lso haplotypes could have been introduced either with the vector or selected within the endemic population of Lso and propagated when environmental conditions were favorable. Previous reports have shown that the main pathway of introducing Lso in regions where the bacterium is absent would be the introduction of the vector. In New Zealand, where the bacterium appeared in 2008, a recent incursion event was thus hypothesized since $B$. cockerelli, which is endemic to America, was accidentally introduced to New Zealand in 2006 from the western United States through plant material (Teulon et al. 2009; Thomas et al. 2011). In Europe, the origin of Lso is unknown. European Lso haplotypes are associated with several psyllid species, including T. apicalis for LsoC in the Scandinavian area, and $B$. trigonica for LsoD in the Canary Islands and Spain. Because of the difference in both psyllid species and psyllid plant hosts in Europe and in America, it is more likely that haplotypes found in Europe (LsoC and LsoD) are native to Europe, as suggested by Nelson et al. (2011, 2013). This hypothesis is supported by the geographic distribution of the psyllid vectors associated with Lso in Europe. The carrot psyllid T. apicalis has been a pest of carrot production for a long time in northern and some parts of central Europe (Munyaneza 2010), whereas B. trigonica is widely distributed in the Mediterranean region (Haapalainen 2014). In France, the psyllid vector(s) transmitting the disease has not yet been identified. However, B. tremblayi, B. nigricornis, and B. trigonica have been formally reported in France (Ouvrard and Burckhardt 2012). These three closely related psyllid species are morphologically similar and belong to the 'Bactericera nigricornis Förster group' (Hodkinson 1981). The 'B. nigricornis group' is composed of multivoltine species (Hodkinson 2009) that feed on a variety of herbaceous plants, including beet, cabbage, carrot, onion, and parsley (Burckhardt and Lauterer 1997), and according to our results some of them are known to be hosts or potential hosts of Lso. These three psyllid species have previously been reported in Spain, with B. trigonica being the predominant species that was found in association with LsoD in carrot plants and likely LsoE in carrot and celery plants (Alfaro-Fernández et al. 2012a, b; Teresani et al. 2014, 2015). Increasing the knowledge of the vector inventory associated with Lso and their population dynamics in France is now necessary to elucidate the biology and development of the bacterium and to mitigate its natural spread.

The present study not only identifies the haplotypes present in France but also clarifies the phylogenetic relationships among Lso haplotypes. To our knowledge, this is the first report evaluating the genetic diversity and phylogenetic relationships among a worldwide collection of isolates representing the five Lso haplotypes. Levels of genetic variation as estimated by polymorphic sites (S), $\theta_{\pi}$ and $\theta_{\mathrm{w}}$ clearly revealed that the $50 \mathrm{~S}$ ribosomal protein $r p I J$-rpIL gene region is the most polymorphic among the ribosomal genes analyzed in this study. Thus, the $r p I J-r p I L$ gene region is well suited for reflecting the phylogenetic relationships among Lso haplotypes. The 50S ribosomal protein has previously been used in the phylogenetic study of other bacteria including ' $\mathrm{Ca}$. L. asiaticus' (Magomere et al. 2009) and Neisseria spp. (Bennett et al. 2014). In the phylogenetic tree constructed on the basis of the $r p I J-r p I L$ gene region sequences, Lso isolates were clustered into five groups that correspond to the five previously described Lso haplotypes, confirming that these haplotypes represent different genetic entities (Haapalainen 2014; Nelson et al. 2011, 2013; Teresani et al. 2014). Our phylogenetic analysis indicates a genetic closeness of LsoD and LsoE. These haplotypes display the same host range within the Apiaceae family in the Mediterranean region and are both associated with $B$. trigonica. Interestingly, our phylogenetic tree grouped LsoD and LsoE isolates within a cluster that was clearly distinct from LsoC isolates. Within the three apiaceous Lso haplotypes, the distinctive nature of LsoC is supported by its association with a different and geographically distant psyllid species (T. apicalis) in the Scandinavian area. Within solanaceous haplotypes, LsoA isolates were found to be separate from LsoB isolates, although displaying the same pathological specificities and the same insect host $(B$. cockerelli). Taken together, our results support the delineation into five haplotypes within Lso, indicating a strong but undetermined biological signification for these groupings. Nelson et al. (2011) reported that the lack of recombinant SNP types in the ribosomal loci strongly suggests long-term separation and divergence of the bacterial populations forming each haplotype. On the contrary, for the rpIJ-rpIL gene region, we detected two recombinant isolates from Spain (JX308305, HQ454307), which grouped into the LsoD cluster. A few recombination events affecting housekeeping genes were previously documented for solanaceous Lso haplotypes in Texas and Nebraska, where LsoA and LsoB showed some range overlap (Glynn et al. 2012). The recombination events detected in both ribosomal genes and housekeeping genes indicate that genetic exchanges were possible between some Lso isolates belonging to haplotypes that display the same symptomatology on the same host range. Further studies, taking into account the overall population structure of Lso by sequencing informative genetic markers (i.e., housekeeping genes), are now being undertaken to propose a tentative scenario for the evolutionary history and haplotype diversification within this complex bacterial species.

Lso epidemiology involves complex interactions between the psyllid vector, a range of host plants, environmental conditions, and bacterial pathogenicity factors. Currently, little is known about Lso pathogenicity determinants. The complete genomic sequences of five isolates derived from solanaceous Lso haplotypes (LsoA and LsoB) have been determined (Lin et al. 2011; Thompson et al. 2015; Wu et al. 2015; Zheng et al. 2014), thus enabling genomewide analysis. Previous comparative genomic studies therefore focused only on Lso solanaceous haplotypes and revealed that differences between haplotypes A and B are present throughout the genome and not restricted to the rRNA operon (Thompson et al. 2015). While LsoA and LsoB haplotypes share a high degree of similarity, this study identified 46 distinct genetic loci present in LsoA but not in LsoB, most of them identified as hypothetical proteins. In addition, Thompson et al. (2015) identified several genomic differences between haplotypes A and B that might promote the evolution and adaptation of these haplotypes to diverse environments and host plants, such as genomic rearrangements, numerous SNPs, and differences in prophage content. Prophages are highly dynamic components in the bacterial genome that play an important role in intraspecies variations and in the evolution of bacterial pathogenicity (Casjens 2003; Varani et al. 2013). In addition, phage integration events appear to play a key role in the genome plasticity of several 'Ca. Liberibacter' species (Lin et al. 2011; Lin and Gudmestad 2013). Prophage regions have been shown to be high-quality markers for differentiating ' $\mathrm{Ca}$. L. asiaticus' isolates from different geographical origins and for determining the source of infection (Katoh et al. 2011, 2015; Matos et al. 2013; Puttamuk et al. 2014; Zhou et al. 2013). Studies concerning these aspects of apiaceous 
Lso haplotypes (LsoC, LsoD, and LsoE) are lacking since no published genome sequences are available for representative strains of these haplotypes. Sequencing of the genome of Lso haplotypes isolated in Europe is now necessary to identify unique genomic regions and prophage regions that may account for host adaptation and the pathogenicity of haplotypes pathogenic on apiaceous plants. These types of studies will also allow the design of haplotype-specific primers for rapid detection and genotype differentiation of European Lso haplotypes.

\section{Acknowledgments}

We thank Charles Manceau for critical reading of the manuscript. This work has received funding from the European Union's Horizon 2020 research and innovation program under grant agreement No 635646, POnTE (Pest Organisms Threatening Europe) and from the French ministry of agriculture under grant agreement C-2015-09 $n^{\circ} 2101755701$ : CaLiso. Both of these projects are dealing with the epidemiology and diagnosis of 'Candidatus Liberibacter solanacearum'.

\section{Literature Cited}

Alfaro-Fernández, A., Cebrián, M. C., Villaescusa, F. J., Hermoso de Mendoza, A., Ferrándiz, J. C., Sanjuán, S., and Font, M. I. 2012a. First report of 'Candidatus Liberibacter solanacearum' in carrots in mainland Spain. Plant Dis. 96:582.

Alfaro-Fernández, A., Siverio, F., Cebrián, M. C., Villaescusa, F. J., and Font, M. I. 2012b. 'Candidatus Liberibacter solanacearum' associated with Bactericera trigonica-affected carrots in the Canary Islands. Plant Dis. 96:581.

Alfaro-Fernández, A., Verdeguer, M., Rodríguez-León, F., Ibáñez, I., Hernández, D., Teresani, G. R., Bertolini, E., Cambra, M., and Font, M. I. 2016. Search for reservoirs of 'Candidatus Liberibacter solanacearum' and mollicutes in weeds associated with carrot and celery crops. Eur. J. Plant Pathol. 132:297-308.

Bennett, J. S., Watkins, E. R., Jolley, K. A., Harrison, O. B., and Maiden, M. C. J. 2014. Identifying Neisseria species using the 50S ribosomal protein L6 ( $r p l F)$ gene. J. Clin. Microbiol. 52:1375-1381.

Burckhardt, D., and Lauterer, P. 1997. Systematics and biology of the Aphalara exilis (Weber and Mohr) species assemblage (Hemiptera: Psyllidae). Entomol. Scand. 28:271-305.

Casjens, S. 2003. Prophages and bacterial genomics: what have we learned so far? Mol. Microbiol. 49:277-300.

Duan, Y. P., Zhou, L. J., Hall, D. G., Li, W. B., Doddapaneni, H., Lin, H., Liu, L., Vahling, C. M., Gabriel, D. W., Williams, K. P., Dickerman, A., Sun, Y., and Gottwald, T. 2009. Complete genome sequence of citrus huanglongbing bacterium, 'Candidatus Liberibacter asiaticus' obtained through metagenomics. Mol. Plant-Microbe Interact. 22:1011-1020.

Fu, Y. X., and Li, W. H. 1993. Statistical tests of neutrality of mutations. Genetics 133:693-709.

Glynn, J. M., Islam, M. S., Bai, Y., Lan, S., Wen, A., Gudmestad, N. C., Civerolo, E. L., and Lin, H. 2012. Multilocus sequence typing of 'Candidatus Liberibacter solanacearum' isolates from North America and New Zealand. J. Plant Pathol. 94:223-228.

Haapalainen, M. 2014. Biology and epidemics of 'Candidatus Liberibacter' species, psyllid- transmitted plant-pathogenic bacteria. Ann. Appl. Biol. 165: 172-198.

Hall, T. A. 1999. BioEdit: a user-friendly biological sequence alignment editor and analysis program for Windows 95/98/NT. Nucleic Acids Symp. Ser. 41:95-98.

Hansen, A. K., Trumble, J. T., Stouthamer, R., and Paine, T. D. 2008. A new Huanglongbing (HLB) species, "Candidatus Liberibacter psyllaurous", found to infect tomato and potato, is vectored by the psyllid Bactericera cockerelli (Sulc). Appl. Environ. Microbiol. 74:5862-5865.

Hodkinson, I. D. 1981. Status and taxonomy of the Trioza (Bactericera) nigricornis Förster complex (Hemiptera: Triozidae). Bull. Entomol. Res. 71:671-679.

Hodkinson, I. D. 2009. Life cycle variation and adaptation in jumping plant lice (Insecta: Hemiptera: Psylloidea): a global synthesis. J. Nat. Hist. 43:65-179.

Jagoueix, S., Bové, J. M., and Garnier, M. 1996. PCR detection of the two Candidatus Liberobacter species associated with greening disease of citrus. Mol. Cell. Probes 10:43-50.

Katoh, H., Inoue, H., and Iwanami, T. 2015. Changes in variable number of tandem repeats in 'Candidatus Liberibacter asiaticus' through insect transmission. PLoS One 10:e138699.

Katoh, H., Subandiyah, S., Tomimura, K., Okuda, M., Su, H. J., and Iwanami, T. 2011. Differentiation of "Candidatus Liberibacter asiaticus" isolates by variable-number tandem-repeat analysis. Appl. Environ. Microbiol. 77:1910-1917.

Kearse, M., Moir, R., Wilson, A., Stones-Havas, S., Cheung, M., Sturrock, S., Buxton, S., Cooper, C., Markowitz, S., Duran, C., Thierer, T., Ashton, B., Meintjes, P., and Drummond, A. 2012. GENEIOUS Basic: an integrated and extendable desktop software platform for the organization and analysis of sequence data. Bioinformatics 28:1647-1649.

Kimura, M. 1980. A simple method for estimating evolutionary rates of base substitutions through comparative studies of nucleotide sequences. J. Mol. Evol. 16:111-120.
Kumar, S., Stecher, G., and Tamura, K. 2016. MEGA7: Molecular Evolutionary Genetics Analysis version 7.0 for bigger datasets. Mol. Biol. Evol. 33 1870-1874.

Li, W., Abad, J. A., French-Monar, R. D., Rascoe, J., Wen, A., Gudmestad, N. C., Secor, G. A., Lee, I. M., Duan, Y., and Levy, L. 2009. Multiplex real-time PCR for detection, identification and quantification of 'Candidatus Liberibacter solanacearum' in potato plants with zebra chip. J. Microbiol. Methods 78:59-65.

Li, W., Hartung, J. S., and Levy, L. 2006. Quantitative real-time PCR for detection and identification of Candidatus Liberibacter species associated with citrus huanglongbing. J. Microbiol. Methods 66:104-115.

Librado, P., and Rozas, J. 2009. DnaSP v5: a software for comprehensive analysis of DNA polymorphism data. Bioinformatics 25:1451-1452.

Liefting, L., Perez-Egusquiza, Z., Clover, G., and Anderson, J. 2008a. A new 'Candidatus Liberibacter' species in Solanum tuberosum in New Zealand. Plant Dis. 92:1474.

Liefting, L. W., Sutherland, P. W., Ward, L. I., Paice, K. L., Weir, B. S., and Clover, G. R. G. 2009a. A new 'Candidatus Liberibacter' species associated with diseases of solanaceous crops. Plant Dis. 93:208-214.

Liefting, L. W., Ward, L. I., Shiller, J. B., and Clover, G. R. G. 2008b. A new 'Candidatus Liberibacter' species in Solanum betaceum (tamarillo) and Physalis peruviana (cape gooseberry) in New Zealand. Plant Dis. 92:1588.

Liefting, L. W., Weir, B. S., Pennycook, S. R., and Clover, G. R. G. 2009b. 'Candidatus Liberibacter solanacearum', associated with plants in the family Solanaceae Int. J. Syst. Evol. Microbiol. 59:2274-2276.

Lin, H., Doddapaneni, H., Munyaneza, J. E., Civerolo, E. L., Sengoda, V. G. Buchman, J. L., and Stenger, D. C. 2009. Molecular characterization and phylogenetic analysis of 16S rRNA from a new "Candidatus Liberibacter" strain associated with zebra chip disease of potato (Solanum tuberosum L.) and the potato psyllid (Bactericera cockerelli Sulc). J. Plant Pathol. 91:215-219.

Lin, H., and Gudmestad, N. C. 2013. Aspects of pathogen genomics, diversity, epidemiology, vector dynamics, and disease management for a newly emerged disease of potato: zebra chip. Phytopathology 103:524-537.

Lin, H., Islam, M. S., Bai, Y., Wen, A., Lan, S., Gudmestad, N. C., and Civerolo, E. L. 2012. Genetic diversity of 'Candidatus Liberibacter solanacearum' strains in the United States and Mexico revealed by simple sequence repeat markers. Eur. J. Plant Pathol. 132:297-308.

Lin, H., Lou, B., Glynn, J. M., Doddapaneni, H., Civerolo, E. L., Chen, C., Duan, Y., Zhou, L., and Vahling, C. M. 2011. The complete genome sequence of 'Candidatus Liberibacter solanacearum', the bacterium associated with potato zebra chip disease. PLoS One 6:e19135.

Ling, K. S., Lin, H., Ivey, M. L. L., Zhang, W., and Miller, S. 2011. First report of 'Candidatus Liberibacter solanacearum' naturally infecting tomatoes in the state of Mexico, Mexico. Plant Dis. 95:1026.

Loiseau, M., Garnier, S., Boirin, V., Merieau, M., Leguay, A., Renaudin, I., Renvoisé, J. P., and Gentit, P. 2014. First Report of 'Candidatus Liberibacter solanacearum' in carrot in France. Plant Dis. 98:839.

Magomere, T. O., Obukosia, S. D., Mutitu, E., Ngichabe, C., Olubayo, F., and Shibairo, S. 2009. Molecular characterization of 'Candidatus Liberibacter' species/strains causing huanglongbing disease of citrus in Kenya. Electron. J. Biotechnol. 12. doi:10.2225/vol12-issue2-fulltext-2

Matos, L. A., Hilf, M. E., Chen, J., and Folimonova, S. Y. 2013. Validation of 'variable number of tandem repeat'-based approach for examination of 'Candidatus Liberibacter asiaticus' diversity and its applications for the analysis of the pathogen populations in the areas of recent introduction. PLoS One 8:e78994

Munyaneza, J. E. 2010. Psyllids as vectors of emerging bacterial diseases of annual crops. Southwest. Entomol. 35:471-477.

Munyaneza, J. E. 2015. Zebra chip disease, Candidatus liberibacter, and potato psyllid: A global threat to the potato industry. Am. J. Potato Res. 92:230-235.

Munyaneza, J. E., Crosslin, J. M., and Upton, J. E. 2007. Association of Bactericera cockerelli (Homoptera: Psyllidae) with "zebra chip", a new potato disease in southwestern United States and Mexico. J. Econ. Entomol. 100:656-663.

Munyaneza, J. E., Fisher, T. W., Sengoda, V. G., and Garczynski, S. F. 2010a. First report of 'Candidatus Liberibacter solanacearum' associated with psyllidaffected carrots in Europe. Plant Dis. 94:639.

Munyaneza, J. E., Fisher, T. W., Sengoda, V. G., Garczynski, S. F., Nissinen, A., and Lemmetty, A. 2010b. Association of "Candidatus Liberibacter solanacearum" with the psyllid Trioza apicalis (Hemiptera: Triozidae) in Europe. J. Econ. Entomol. 103:1060-1070.

Munyaneza, J. E., Sengoda, V. G., Crosslin, J. M., De la Rosa-Lozano, G., and Sanchez, A. 2009. First report of 'Candidatus Liberibacter psyllaurous' in potato tubers with zebra chip disease in Mexico. Plant Dis. 93:552.

Munyaneza, J. E., Sengoda, V. G., Stegmark, R., Arvidsson, A. K., Anderbrant, O., Yuvaraj, J. K., Rämert, B., and Nissinen, A. 2012a. First report of "Candidatus Liberibacter solanacearum" associated with psyllid-affected carrots in Sweden. Plant Dis. 96:453.

Munyaneza, J. E., Sengoda, V. G., Sundheim, L., and Meadow, R. 2012b. First report of "Candidatus Liberibacter solanacearum" associated with psyllidaffected carrots in Norway. Plant Dis. 96:454

Munyaneza, J. E., Swisher, K. D., Hommes, M., Willhauck, A., Buck, H., and Meadow, R. 2015. First Report of 'Candidatus Liberibacter solanacearum' Associated With Psyllid-Infested Carrots in Germany. Plant Dis. 99:1269. 
Murphy, A. F., Cating, R. A., Goyer, A., Hamm, P. B., and Rondon, S. I. 2014. First report of natural infection by 'Candidatus Liberibacter solanacearum' in bittersweet nightshade (Solanum dulcamara) in the Columbia basin of eastern Oregon. Plant Dis. 98:1425.

Murray, M. G., and Thompson, W. F. 1980. Rapid isolation of high molecular weight plant DNA. Nucleic Acids Res. 8:4321-4326.

Nei, M. 1987. Molecular Evolutionary Genetics. Columbia Univ. Press, New York.

Nelson, W. R., Fisher, T. W., and Munyaneza, J. E. 2011. Haplotypes of "Candidatus Liberibacter solanacearum" suggest long-standing separation. Eur. J. Plant Pathol. 130:5-12.

Nelson, W. R., Sengoda, V. G., Crosslin, J. M., Alfaro-Fernández, A. O., Font, M. I., and Munyaneza, J. E. 2013. A new haplotype of "Candidatus Liberibacter solanacearum" in the Mediterranean region. Eur. J. Plant Pathol. 135:633-639.

Nissinen, A. I., Haapalainen, M., Jauhiainen, L., Lindman, M., and Pirhonen, M. 2014. Different symptoms in carrots caused by male and female carrot psyllid feeding and infection by 'Candidatus Liberibacter solanacearum'. Plant Pathol. 63:812-820.

Ouvrard, D., and Burckhardt, D. 2012. First record of the onion psyllid Bactericera tremblayi (Wagner, 1961) in France (Insecta: Hemiptera: Sternorrhyncha: Psylloidea), new symptoms on leek crops and reassessment of the B. nigricornis group distribution. Bull. OEPP 42:585-590.

Pitman, A. R., Drayton, G. M., Kraberger, S. J., Genet, R. A., and Scott, I. A. W. 2011. Tuber transmission of 'Candidatus Liberibacter solanacearum' and its association with zebra chip on potato in New Zealand. Eur. J. Plant Pathol. 129:389-398.

Puttamuk, T., Zhou, L. J., Thaveechai, N., Zhang, S. A., Armstrong, C. M., and Duan, Y. P. 2014. Genetic diversity of Candidatus Liberibacter asiaticus based on two hypervariable effector genes in Thailand. PLoS One 9:e112968.

Secor, G. A., Rivera-Varas, V., Abad, J. A., Lee, I. M., Clover, G. R. G., Liefting, L. W., Li, X., and De Boer, S. H. 2009. Association of 'Candidatus Liberibacter solanacearum' with zebra chip disease of potato established by graft and psyllid transmission, electron microscopy, and PCR. Plant Dis. 93:574-583.

Soliman, T., Mourits, M. C. M., Oude Lansink, A. G. J. M., and van der Werf, W. 2013. Economic justification for quarantine status - the case study of Candidatus Liberibacter Solanacearum in the European Union. Plant Pathol. 62:1106-1113.

Tahzima, R., Maes, M., Achbani, E. H., Swisher, K. D., Munyaneza, J. E., and De Jonghe, K. 2014. First Report of 'Candidatus Liberibacter solanacearum' on Carrot in Africa. Plant Dis. 98:1426.

Tajima, F. 1989. Statistical method for testing the neutral mutation hypothesis by DNA polymorphism. Genetics 123:585-595.

Teresani, G. R., Bertolini, E., Alfaro-Fernández, A., Martínez, C., Tanaka, F. A. O., Kitajima, E. W., Roselló, M., Sanjuán, S., Ferrándiz, J. C., López, M. M., Cambra, M., and Font, M. I. 2014. Association of 'Candidatus Liberibacter solanacearum' with a vegetative disorder of celery in Spain and development of real-time PCR method for its detection. Phytopathology 104:804-811.

Teresani, G. R., Hernández, E., Bertolini, E., Siverio, F., Marroquín, C., Molina, J., Hermoso de Mendoza, A., and Cambra, M. 2015. Search for potential vectors of
'Candidatus Liberibacter solanacearum': Population dynamics in host crops. Span. J. Agric. Res. 13:e10-002.

Teulon, D. A. J., Workman, P. J., Thomas, K. L., and Nielsen, M. C. 2009. Bactericera cockerelli: incursion, dispersal and current distribution on vegetable crops in New Zealand. N. Z. Plant Prot. 62:136-144.

Thinakaran, J., Pierson, E., Kunta, M., Munyaneza, J. E., Rush, C., and Henne, D. 2015. Silverleaf nightshade (Solanum elaeagnifolium) a reservoir host for 'Candidatus Liberibacter solanacearum', the putative causal agent of zebra chip disease of potato. Plant Dis. 99:910-915.

Thomas, K. L., Jones, D. C., Kumarasinghe, L. B., Richmond, J. E., Gill, G. S. C., and Bullians, M. S. 2011. Investigation into the entry pathway for the tomato potato psyllid Bactericera cockerelli. N. Z. Plant Prot. 64:259-268.

Thompson, S. M., Johnson, C. P., Lu, A. Y., Frampton, R. A., Sullivan, K. L. Fiers, M. W. E. J., Crowhurst, R. N., Pitman, A. R., Scott, I. A. W., Wen, A., Gudmestad, N. C., and Smith, G. R. 2015. Genomes of 'Candidatus Liberibacter solanacearum' haplotype A from New Zealand and the United States suggest significant genome plasticity in the species. Phytopathology 105:863-871.

Varani, A. M., Monteiro-Vitorello, C. B., Nakaya, H. I., and Van Sluys, M. A 2013. The role of prophage in plant-pathogenic bacteria. Annu. Rev. Phytopathol. 51:429-451.

Vereijssen, J., Taylor, N. M., Barnes, A. M., Thompson, S. E., Logan, D. P. Butler, R. C., Yen, A. L., and Finlay, K. J. 2015. First report of 'Candidatus Liberibacter solanacearum' in Jerusalem cherry (Solanum pseudocapsicum) and thorn-apple (Datura stramonium) in New Zealand. New Dis. Rep. 32:1

Watterson, G. A. 1975. On the number of segregating sites in genetical models without recombination. Theor. Popul. Biol. 7:256-276.

Wen, A., Johnson, C., and Gudmestad, N. C. 2013. Development of a PCR assay for the rapid detection and differentiation of 'Candidatus Liberibacter solanacearum' haplotypes and their spatiotemporal distribution in the United States. Am. J. Potato Res. 90:229-236.

Wen, A., Mallik, I., Alvarado, V. Y., Pasche, J. S., Wang, X., Li, W., Levy, L., Lin, H., Scholthof, H., Mirkov, E., Rush, C. M., and Gudmestad, N. C. 2009. Detection, distribution, and genetic variability of 'Candidatus Liberibacter' species associated with the zebra complex disease of potato in the North America. Plant Dis. 93:1102-1115.

Wu, F., Deng, X., Liang, G., Cen, Y., Wallis, C., Trumble, J. T., Prager, S., and Chen, J. 2015. De Novo genome sequence of "Candidatus Liberibacter solanacearum" from a single potato psyllid in California. Genome Announc. 3:e01500-15.

Zheng, Z., Clark, N., Keremane, M., Lee, R., Wallis, C., Deng, X., and Chen, J. 2014. Whole-genome sequence of "Candidatus Liberibacter solanacearum" strain R1 from California. Genome Announc. 2:e1353-14.

Zhou, L., Powell, C., Li, W., and Duan, Y. 2013. Prophage-mediated dynamics of 'Candidatus Liberibacter asiaticus' populations, the destructive bacterial pathogens in citrus huanglongbing. PLoS One 8:e82248. 